\title{
Erratum to: Expression of human apolipoprotein A-I in Nicotiana tabacum
}

\author{
Pasquale Chiaiese $\cdot$ Maria Minutolo • \\ Angela Arciello · Fulvio Guglielmi • \\ Renata Piccoli • Edgardo Filippone
}

Published online: 22 October 2010

(C) Springer Science+Business Media B.V. 2010

\section{Erratum to: Biotechnol Lett \\ DOI 10.1007/s10529-010-0388-4}

Unfortunately, in the original publication of this article the name of one of the authors is incorrect. The correct spelling is: Fulvio Guglielmi.

Pasquale Chiaiese, Maria Minutolo contributed equally to this work.

The online version of the original article can be found under doi:10.1007/s10529-010-0388-4.

P. Chiaiese $(\bowtie) \cdot$ M. Minutolo · E. Filippone Department of Soil, Plant, Environmental and Animal Production Sciences, School of Biotechnological Sciences, University of Naples Federico II, Naples, Italy e-mail: chiaiese@unina.it

\section{A. Arciello · F. Guglielmi · R. Piccoli} Department of Structural and Functional Biology, School of Biotechnological Sciences, University of Naples Federico II, Complesso Universitario di Monte S. Angelo Via Cinthia 4, 80126 Naples, Italy

A. Arciello $\cdot$ R. Piccoli Istituto Nazionale di Biostrutture e Biosistemi (INBB), Rome, Italy 